\title{
THE EFFICACY OF SCOLIOSIS TREATMENT USING SCHROTH METHOD FOR CHILDREN AND TEENAGERS BREATHING AND POSTURE PARAMETERS
}

\author{
Darasevič Karol'1, Raistenskis Juozas ${ }^{1,2}$, Sinkevičius Romualdas ${ }^{1,2}$ \\ ${ }^{1}$ Children's Hospital, Affiliate of Vilnius University Hospital Santaros Klinikos \\ 2 Vilnius University Faculty of Medicine Department of Rehabilitation, Physical and Sports \\ Medicine
}

Introduction: The main objective of rehabilitation is to reduce the degree of scoliosis and prevent the emergence of secondary symptoms, such as back pain, respiratory problems, cosmetic deformities and quality of life. Only a well-prepared, individualized program with specialist care helps to slow or reduce adolescent idiopathic scoliosis.

Purpose: Evaluate Schroth method for children and teenagers with idiopathic scoliosis breathing and posture parameters and compare with traditional physical therapy.

Method: The study wa carried out between october 2016 and april 2017 at Children's Hospital, Affiliate of Vilnius University Hospital Santaros Klinikos. In study participated 9-16 years old children and teenagers with diagnosed idiopathic scoliosis $(n=33)$. Participants were divided in two groups: the study $(n=20)$ and control $(n=11)$. Study group was designated with Schroth method and control with traditional physiotherapy. Both groups have applied 10 procedures of physiotherapy, five time per week, one procedure lasted $30 \mathrm{~min}$. Chest wall excursion measurements, breath hold tests, Trunk Appearance Perception Scale (TAPS-(phys)), Trunk Aesthetic Clinical Evaluation (TRACE) and DIERS Formetric 4D measurement were used. SPSS 21.0 and MS Excels were used for statistic analysis.
Results: After 10 sessions using the Schroth method breath holding test, chest excursion results, trunk appearance scales and other tests results does not statistically significantly differ with control group. Traditional physical therapy group significantly improved posture evaluation using Trunk Appearance Scale for physicians (TAPS-Phy) and this test results only were significantly different after 10 sessions compared to Schroth group.

Conclusions: The conclusion is that traditional physical therapy procedure is more effective treatment for scoliosis in comparison with the Schroth method, but 10 sessions is not enough to receive more significant posture and respiratory functions parameters improvement using both methods.

\section{General characteristics of the subjects. ( ${ }^{*} p>0.05$ between the two groups)}

\begin{tabular}{|c|c|c|c|}
\hline Parameters & Schroth group & $\begin{array}{c}\text { Traditional } \\
\text { physiotherapy }\end{array}$ & $p$ value \\
\hline Number of researches & 20 & 11 & \\
\hline Age + /- sd & $13+/-4$ & $15+/-1$ & 0,260 \\
\hline Sex & female=14, male $=6$ & $\begin{array}{c}\text { female }=5, \\
\text { male }=6\end{array}$ & 0,187 \\
\hline Height $(\mathrm{cm})+/-\mathrm{sd}$ & $159+/-10$ & $168+/-12$ & 0,139 \\
\hline Weight $(\mathrm{kg})+/-\mathrm{sd}$ & $47+/-12$ & $51+/-10$ & 0,476 \\
\hline
\end{tabular}

